\title{
HIV and COVID-19 in Latin America and the Caribbean
}

\author{
Patricia J. Garcia' ${ }^{1}$ Diego M. Cabrera ${ }^{1,2} \cdot$ Paloma M. Cárcamo ${ }^{1} \cdot$ Monica M. Diaz ${ }^{1,3}$
}

Accepted: 8 November 2021 / Published online: 29 January 2022

(c) Springer Science+Business Media, LLC, part of Springer Nature 2021

\begin{abstract}
Purpose of Review Latin America and the Caribbean (LAC) has been hit hard by COVID-19 due to political instability, flawed health systems, and structural inequalities. The repercussion of the pandemic on vulnerable populations, like people living with HIV (PLWH), is complex. This review aims to explore the interactions between the HIV and COVID-19 pandemics in this region.

Recent Findings Data regarding the interactions of HIV and COVID-19 in LAC is scarce. Only case reports or small case series have been published regarding the clinical course of COVID-19 in PLWH and regarding the clinical course of COVID19 in PLWH, which appears to be similar to the general population. The pandemic has disrupted prevention and treatment of PLWH. However, there have been country efforts to counteract those effects. There are some lessons from the HIV response which have been effectively applied in the region to address COVID-19.

Summary COVID-19 has had an unprecedented impact on the cascade-of-care among PLWH in LAC. There is a need for longitudinal studies that assess clinic implication of these pandemic interactions in LAC.
\end{abstract}

Keywords Coronavirus infections $\cdot$ COVID-19 $\cdot$ HIV $\cdot$ AIDS $\cdot$ Latin America $\cdot$ Caribbean

\section{Introduction}

The coronavirus disease 2019 (COVID-19) pandemic began in Wuhan, China in 2019 and quickly spread to the rest of the world. This virus has had profound consequences worldwide

This article is part of the Topical Collection on The Global Epidemic

Patricia J. Garcia

patricia.garcia@upch.pe

Diego M. Cabrera

diego.cabrera.c@upch.pe

Paloma M. Cárcamo

paloma.carcamo.g@upch.pe

Monica M. Diaz

monica.diaz@neurology.unc.edu

1 School of Public Health, Cayetano Heredia University, Av. Honorio Delgado 430, San Martin de Porres, Lima 31, Peru

2 Section of Rheumatology, Allergy and Immunology, Yale School of Medicine, 330 Cedar Street, New Haven, CT 06510, USA

3 Department of Neurology, University of North Carolina at Chapel Hill, 170 Manning Drive, Campus Box 7025, Chapel Hill, NC 27599, USA but especially in low-and-middle income countries (LMIC), where healthcare and related resources are typically sparsely available and inequitably distributed [1]. Latin America and the Caribbean (LAC) has been hit hard by COVID-19. The first confirmed COVID-19 case in LAC happened in Brazil on February 25th, 2020 [2], and the first death was reported in Argentina on March 7th, 2020 [3]. By March 19th, every Latin American country had reported cases of COVID-19. The region has had one of the highest COVID-19 death rates in the world, due to a combination of political instability, corruption, flawed health systems, and deeply ingrained structural inequalities [4••].

The literature suggests that the presence of comorbidities, such as coronary artery disease, obesity, diabetes, and hypertension, are important risk factors for severity of COVID$19[5,6]$. However, there is also growing concern for the direct and indirect effects of COVID-19 on people with other chronic conditions, such as HIV infection. The impact that COVID-19 could have on this population is complex: Although people living with HIV (PLWH) could potentially develop abnormal cellular and humoral responses leading to higher risk of infections, in the past couple of decades, access to ART has enabled PLWH to live longer by achieving viral suppression $[7,8]$. However, they are exposed to 
the additive challenges of long-term secondary effects of lifelong medication and HIV infection, possibility leading to early manifestations of other chronic comorbidities like cardiovascular or metabolic pathologies, both of which might put them at higher risk of COVID-19 adverse outcomes [9]. Another aspect to consider are social determinants of health which could place PLWH at a higher risk of exposure. Moreover, the pandemic and consequent establishment of nationwide lockdowns could have affected various services for PLWH, including testing, preventive interventions, and treatment [10].

In 2019, the UNAIDS estimated that at least 2.4 million people live with HIV in LAC. There has been a slow progress in the region achieving the UNAIDS 90-90-90 goals: In $2019,60 \%$ of PLWH were on antiretroviral therapy (ART) and 53\% had achieved viral suppression compared to 53\% and $44 \%$ in 2015. Additionally, since 2010, new HIV infections are on the rise in LAC, with $21 \%$ more new infections, and only $8 \%$ decrease on AIDS-related deaths [11]. In this context, it becomes urgent to understand the effects and impacts that the COVID-19 pandemic may have on PLWH in LAC. In this review, we summarized the interactions between the HIV and COVID-19 pandemics in the region of LAC.

\section{Impact of HIV on the Infection Risk and Severity of COVID-19 in LAC}

Early in the pandemic, there were global concerns about the interactions of HIV and COVID-19 based on studies showing higher mortality in PLWH compared with general population during seasonal influenza [12].

However, studies mainly from Europe and the USA suggest that PLWH are not more susceptible than the general population to SARS-CoV-2 infection, but they are more likely to be tested and to have similar clinical outcomes than patients who are HIV negative [13], although the largest population-based study to address the risk of death from COVID-19 on PLWH, done in South Africa, found a higher mortality rate in this population, which could be associated with the burden of other comorbidities [14].

The Latin American literature on the impact of HIV on the infection risk and severity of COVID-19 is scarce, and mainly based on case reports or small case series. A study from Mexico City based on a single-center review of eleven HIV-infected patients diagnosed with COVID-19 between March and May 2020 found that only 9/11 PLWH were hospitalized, most have comorbidities (obesity 70\%, hypertension 30\%), and despite critical clinical presentations, most made a full recovery. They conclude that outcomes were similar to those seen for HIV-negative persons [15]. An observational study in Chile recruited all PLWH with confirmed SARS-CoV-2 infection and hospitalized in any of 23 hospitals of eight regions. Of the 15 patients enrolled between April and June 2020, 92\% were men with a mean age of 44 years old and $80 \%$ were on ART and good virologic control. PLWH were more likely to be admitted to an ICU, but the rates of mechanical ventilation and death were similar to that of the Chilean general population. Hypertension and cardiovascular comorbidities were the most important risk factors for mortality in these PLWH [16••].

PLWH remain susceptible to COVID-19 even when virally suppressed, or when receiving ART in both outpatient and in-patient settings [17]. A case report from Peru highlighted the potential for in-hospital-acquisition of COVID-19 in PLWH hospitalized for HIV-associated complications [18]. ART was previously hypothesized to affect the course of COVID-19 in PLWH due to antiviral activity. Some antiretroviral drugs, such as lopinavir-ritonavir, have already been shown not to be effective in hospitalized patients with COVID-19 [19-21]. However, other studies seem to suggest a positive effect of chronic ART on COVID19 outcomes in PLWH [22]. Tenofovir/emtricitabine might have a protective effect, though there is no definitive evidence yet [23]. A case series of $8 \mathrm{HIV}$-infected kidney transplant recipients in Brazil seemed to suggest that ART does not mitigate the poor outcomes of COVID-19 in this population, though they have the additional risk factor of solid organ transplant-related immunosuppressive treatment [24].

Other coinfections have been described in Latin America during SARS-CoV-2 infection in PLWH. One case from Argentina described a woman with a new diagnosis of advanced HIV, diagnosed with COVID-19 and Pneumocystis jirovecii simultaneously, who had a favorable evolution after treatment [25]. Histoplasma capsulatum is an emergent systemic fungal infection in several Latin American countries, with an estimated median seropositivity of $22 \%$ in the general population and even higher infection rates in PLWH [26]. This fungal infection has been reported as a coinfection in PLWH and COVID-19 in a few case reports [27-29]. Another coinfection described in the literature is SARS-CoV-2 and Mycobacterium tuberculosis in PLWH, which is a matter of concern and has not been well studied [30, 31]. Mycobacterium tuberculosis coinfection detection and prompt treatment are crucial as it could increase COVID-19 susceptibility, and have been well described as an independent risk factor for COVID-19 severity and mortality, irrespective of HIV status [32, 33]. For PLWH, the risk is even higher, as tuberculosis is already the leading cause of death among this population, accounting for about 270,000 deaths in 2019 [34].

These case reports reflect the importance of investigating coinfections in SARS-CoV-2/HIV patients, and of having readily available diagnostic tests according to the local epidemiology. 


\section{Impact of the COVID-19 Pandemic on HIV Prevention and Care of PLWH in LAC}

The collision of COVID-19 and HIV has disrupted the global HIV response and its advance, since services and supply chains have been affected [35].

In March 2020, the World Health Organization (WHO) released operational guidelines to maintain essential health services throughout the COVID-19 pandemic [36]. It was followed by another document in June 2020, which emphasized the importance of maintaining an effective HIV response during the public health emergency through multi-month prescriptions and dispensing of PrEP, ART, and prophylaxis for common comorbidities; enabling of community dispensing points; implementation of online or telephone counseling for HIV testing while prioritizing high-risk individuals; implementation of HIV selftesting (HIVST); and reducing viral load testing to every 12 months unless there is a clear clinical indication [37]. The Pan American Health Organization (PAHO) also released at the beginning of the LAC pandemic recommendations on COVID-19 prevention and HIV care delivery adjustments to be made [38]. However, these recommendations have been followed to varying degrees across countries in LAC.

\section{HIV Testing and Prevention}

There has been clearly a decrease in routine HIV testing worldwide in 2020 [35]. The WHO recommends HIVST as an additional strategy for HIV prevention [39, 40]. The utility of HIVST in LAC is worth noting as it has the advantages of reducing the risk of contagion associated with use of public transport, reducing lines in facilitybased HIV testing, and avoiding the issue of privacy given stigma often associated with HIV in LAC [41].

One survey of 680 Brazilian MSM on PrEP found that the willingness to use HIVST was $79 \%$ and $32 \%$ had HIVST during the quarantine [42]. HIVST has also been proposed in the Caribbean as a measure to mitigate the lack of routine HIV testing in laboratories and minimize risk of exposure and infection; however, only the Bahamas and Jamaica have implemented guidelines on its use $[43 \bullet \bullet]$.

Although there are no reports of the lack of barrier prevention methods from LAC during 2020, the COVID-19 pandemic is expected to have had adversely affected the supply chain by disrupting the manufacture of components of condoms and by delaying their transportation particularly in LMIC [44, 45]. Reductions of equipment and staff involved in the provision of sexual and reproductive health services during the pandemic, closure of clinics offering these services, and reluctance of persons to attend health facilities for these services may also affect the distribution of barrier prevention methods.

However, there is one publication of successful implementation of condom and PrEP home delivery as part of a study with Brazilian adolescent men who have sex with men (MSM) and transgender individuals [46].

Brazil has been offering free access to PrEP to high-risk populations for HIV infection since 2018 [47]. During the pandemic, they continue providing these services introducing different strategies like extending the dispense to 120 day supplies [48]. A study conducted in southeastern Brazil with sexual minority populations reported that nearly $70 \%$ continued daily oral PrEP during the pandemic, and among those who reported having stopped it, the most common reasons were impediments to pick up their PrEP refills at their HIV clinic [49]. Another study of patients from Sao Paulo, Brazil found that oral PrEP use was associated with lower self-reporting of COVID-19-related symptoms during the pandemic after controlling for confounders such as age and social distancing frequency [50]. Nonetheless, the number of people benefiting from PrEP in Brazil seems to have continued to grow steadily despite the pandemic, with 8108 people starting in 2018, 8536 in 2019, and 10,120 until October, 2020 [51]. Conversely, worldwide, there seem to be diminishing numbers of people receiving PrEP, perhaps in part due to a reduction in sexual activity due to social distancing recommendations, interruptions in supply chains, and lack of access to services [52].

\section{Access to HIV Care}

Early in the pandemic, modelers estimated that HIV mortality in the next 5 years could be increased by 10-36\% depending on the level of disruptions on HIV services, especially in the provision of ART [53]. The UNAIDS has been working with countries trying to track the HIV service utilization which has been showing, when the data is available, clear disruptions in many countries, with important drops in treatment coverage in LAC in countries like the Dominican Republic, Guyana, and Peru [35]. There have been also reductions in the number of PLWH initiating treatment in several countries, with at least one country from LAC, the Dominican Republic, with a steady and worrisome decline.

Attempts have been made by Ministries of Health in LAC to maintain the ART supply during the pandemic. New guidelines have been set up to ensure continuity of care for PLWH while reducing their risk of infection during the pandemic. These guidelines include, for example, multi-month prescriptions of ART and permitting pickup of ART by healthy family members [51,54-58]. An article written by a Brazilian government representative stated that 
there had been no decrease in the number of people being treated for HIV in the country due to the national HIV program measures implemented [51]. However, an independent report found that the slowing down of government-run AIDS programs due to stay-at-home orders had forced non-governmental organizations to step up and ensure that PLWH received much-needed ART [59]. In a study of Brazilian sexual minorities with a large population of PLWH, 18\% reported poor ART adherence during social distancing [49], emphasizing the variability in availability of ART and barriers to their access across the same country [60, 61].

At the start of the pandemic, Costa Rica quickly assembled special teams and locations, and enabled electronic prescriptions and mailing of medication to chronic patients to ensure continuity of ART, but the results were mixed. One local news outlet reported that though there was no shortage of medications, patients experienced delays of up to 15 days in receiving ARTs. Additional barriers to receiving treatment were identified for indigenous and remote communities, communities living in poverty, and undocumented migrants, partly due to lack of connectivity [62].

In a study among middle-aged to older Peruvians with HIV, PLWH reported difficulty accessing ART due to clinic closures or long lines; however, 97\% reported adherence with ART [63••].

Caribbean countries are facing the challenges of overcrowded hospitals and limited access to healthcare workers, increasing the risk that patients with HIV may not initiate appropriate treatment in a timely manner [64]. In one study of patients with HIV in Haiti, the mean number of HIV visits fell from 121.5 to 92.5 visits over a 16 -week period, and an abrupt decline of ART refills by $18 \%$, demonstrating the changes in HIV care utilization that occurred in Haiti during the pandemic [65].

Several LAC countries have implemented guidelines that promote using mobile phones and social networks to monitor stable patients, and teleconsultations for those that require visits. Some have opted to space out appointments for stable patients, and most have postponed CD4 and viral load measurements indefinitely [54-57]. One multi-country Latin American survey including HIV services participating in the Caribbean, Central and South America network for HIV epidemiology (CCASAnet) and additional Brazilian HIV care sites in Argentina, Brazil, Chile, Haiti, Honduras, Mexico, and Peru found that most surveyed sites reported decreased hours and providers for HIV care (11/13 sites), increased use of telehealth (12/13), and suspension or deferral of routine HIV appointments (12/13) [66]. In Brazil, the government has begun to implement telemedicine services, and digitized laboratory exam requests, certificates, and prescriptions [51]. Nearly one-third of Brazilian PLWH in one study reported changing the form of HIV care received from in-person care to teleconsultation [67]. In another study of
Brazilian PLWH, 21\% had a PrEP teleconsultation during the pandemic with $70 \%$ reporting it as acceptable [68]. In one Argentinian study, 35\% of respondents reported being unable to access medical care due to lack of connectivity, but only $4 \%$ reported problems obtaining ART [69]. This demonstrates that longer supplies of ART provided by clinics may have prevented ART interruption despite lack of access to an HIV care provider. Similarly, another study of MSM (including respondents from Brazil and Mexico and a substantial proportion of PLWH) found that $23 \%$ lost access to their HIV providers due to quarantine measures and only $17 \%$ had access to telehealth services [70]. Despite the acceptability of telemedicine among $70 \%$ of Brazilian PLWH [42], the reality of implementation of these services faces the challenges of clinics not having the equipment for telehealth services and patients not having access to smartphones or stable internet connections.

\section{Overlap Between HIV-Related and COVID-Related Stigma in LAC}

Stigma associated with HIV is known to be prevalent in LMIC and is detrimental to HIV care, particularly in that it prevents PLWH from receiving care for fear of being persecuted or rejected from their communities [71]. The authors of one study have proposed that some drivers of stigma related to COVID-19 significantly overlap with those observed during the HIV pandemic and the Ebola outbreaks, including lack of information or misinformation and misconceptions about how the disease spreads [72]. This may lead to specific individuals being singled out as causes or carriers of the disease, increasing the stigma associated with the disease. Fear of contagion drives prejudice and stereotypes of the individuals affected by the disease. Even healthcare workers face stigmatization as they are seen as possible carriers of the disease. Policies that single out and separate vulnerable groups of people for their own protection or the protection of others also bolster stigma associated with the disease.

In Latin America, in particular, groups that are known to be more vulnerable to both HIV-related and COVID-19-related stigma include those in poverty or informal workers, minority ethnicities, and persons of genders or sexual orientations that may be chastised for their sexual preference

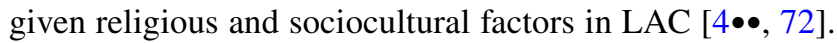
Notably, in LAC, several countries including Panama, Peru, and Colombia (only in Bogota) implemented policies to enforce physical distancing and mobility restrictions on its citizens based on binary understandings of gender. On alternating days, either men or women could go outside for their daily needs, further validating these gender-based binary ideologies that are often accepted as "norms" in many LAC cultures. These laws placed transgender people in a gray 
zone of when they are legally allowed to access services such as food and medical supplies [73].

\section{Mental Health Impact of the COVID-19 Pandemic on PLWH in LAC}

PLWH are known to be at higher risk of mental health challenges compared with the general population [74]. And given other vulnerabilities common among PLWH in LMIC (poverty, being informal workers, food insecurity, etc.), mental health impacts are particularly important to be explored in PLWH in LAC during the pandemic. Community-based support groups, which may have helped PLWH to cope, have often had to be suspended during the lockdowns. The multicountry Latin American survey on HIV services mentioned before in this article found that in 12 out of 13 participating sites, community-based support activities had to be partially or completely canceled due to the pandemic [66]. One international study consisting of nearly $30 \%$ PLWH from Brazil found that nearly one-quarter reported depressive disorders and $16 \%$ reported both anxiety and depression, which was less than the reported frequency of mental health disorders among PLWH prior to the pandemic [67]. In another study in Peru, $64 \%$ of the PLWH surveyed reported increased stress and $77 \%$ reported increased anxiety during the pandemic [63••].

In a survey among 1336 PLWH from Argentina, 11\% reported disruption of their routine mental health services, $33 \%$ reported less adherence to ART and 1.3\% disruption of substance abuse treatment. Among those who endorsed more resilience in coping, the relationship between economic hardship and mental health challenges was mitigated by their resilient coping style [69]. In another study including the same group of PLWH from Argentina and another group of PLWH from the USA, social support and resilient coping skills contributed to lower rates of depression among Argentinian compared with the American PLWH [75]. This highlights the importance of continuation of mental health services, particularly, mental health interventions that focus on building resilience and more adaptive coping skills during this tenuous pandemic period [76].

\section{Socioeconomic Impact During the Pandemic Among PLWH in LAC}

Economic hardship and food insecurity have increased during the pandemic worldwide. In Peru, a study with PLWH showed that nearly half of those who were employed prior to the pandemic reported job loss [63••]. A survey in PLWH from Argentina reported that more than $40 \%$ experienced economic hardship during the pandemic [69]. Food insecurity is associated with suboptimal ART adherence and poor HIV control. The increased risk of food insecurity among
PLWH and the socioeconomic hardship and high prevalence of informal workers without steady contracted wages in LAC put PLWH in LAC at potentially higher risk of ART nonadherence and poor virologic control [77].

\section{Lessons from HIV Applied for the COVID-19 Pandemic from LAC}

Four decades ago, the HIV pandemic swept through the world, affecting health systems and socioeconomic structures everywhere. Since then, almost 32 million people have died of HIV-related causes around the globe [78]. Similarly, the COVID-19 pandemic has also shaken the world's foundations, exposing the great inequities in our countriesespecially in the LAC - and the weaknesses of our health systems and exacerbating social, political, and economic issues. Despite differences in these viruses, both HIV and COVID-19 generate fear, stigma, and anxiety related to transmission concerns, and both tend to affect marginalized communities with intersecting identities, exacerbating disparities that are already very prevalent in LAC, as evidenced by the disease risk and case fatality rates in the region [79]. Though the overall health status of individuals in LAC has improved in the past decades, progress remains unequal across and within countries. Furthermore, many LAC nations have important gaps in health access caused by political instability, budgetary constraints, and fragmented health services, among other issues [ $4 \bullet \bullet]$.

The HIV epidemic has taught us that scientific evidence by itself is not sufficient to end fear and combat stigma; additional efforts are required too in public health: Community actors, youth, and women's organization, among others, must be included in national responses [78]. As an example, in the Dominican Republic, early in the HIV epidemic, it was considered a hidden disease, making affected individuals especially susceptible to stigmatization. Now, the Dominican Republic's COVID-19 response is a hybrid of previous experiences involving massive educational resources and community engagement [80]. The UNAIDS emphasizes the importance of community-led responses, combating all forms of stigma and discrimination, including those based on race, social contacts, profession, and those directed towards marginalized groups that prevent them from accessing care [81].

Another lesson from the HIV pandemic is to take advantage of all components of healthcare systems. Globally it has been recognized that the successful global response to the HIV epidemic is due to the strengthening of all pillars of the health system [82]. In LAC, Cuba repurposed strategies that were initially created to fight the HIV pandemic have been used to face the threat of COVID-19 [83]. In 1986, amid widespread international controversy, Cuba instituted 
a mandatory quarantine policy for PLWH in order to curb infection rates, creating sanatoriums across the country [84]. They trained healthcare workers in contact tracing and rigorously tested anyone with risk factors. Though the quarantine was lifted in 1994, sanatoriums continued to function both as housing for PLWH and as centers for counseling and care. When the first cases of COVID-19 were reported in the country, the government decided to turn those capacities into an efficient system for contact tracing and isolation of cases. Sanatoriums were used as quarantine centers and well-trained contact tracers were sent into the community, using previous experience with HIV, to curb the spread of the epidemic, which kept the number of cases lower compared with what has been seen in other Latin American countries [83].

Involving civil society organizations is another lesson from HIV to the COVID-19 pandemic. In Venezuela, where a humanitarian crisis has all but collapsed the health system for much of the past decade, civil society organizations and international allies have played a pivotal role in ensuring continuity of care for HIV patients throughout the crisis. Many of the systems put in place by these organizations are so robust that during the COVID-19 pandemic they were easily adapted to face new challenges. For example, civil society organizations established a mechanism to monitor and document the availability of ART in government pharmacies to strengthen advocacy efforts. This monitoring system was adapted to monitor stocks of personal protective equipment during the COVID-19 pandemic, helping to keep health workers safe [85].

\section{Conclusion}

In this review, we have synthesized the information available regarding the interaction of the HIV and COVID-19 pandemics in LAC. Data published regarding the impact of HIV on the infection risk and severity of COVID-19 is scarce in the region and mainly based on case reports or small case series, some referring to coinfections of HIV, COVID-19, and opportunistic infections. In addition, the pandemic has had an important impact on PLWH, with disruption of the continuity-of-care cascade in terms of prevention, access to treatment, and follow-up. However, many Ministries of Health around LAC have promptly responded with HIVST, extension of medication supplies (including PrEP and ART), and providing telehealth services to PLWH and other strategies with variable results. However, there is still a need to document and quantify better the short-term, mediumterm, and long-term effects of the HIV service disruptions in the LAC. Finally, we also report lessons learned from HIV applied in some Latin American countries to deal with the COVID-19 pandemic such as community engagement, take advantage of all components of healthcare systems, and adapt them during the crisis and the involvement of the civil society organizations and international allies. Being Latin America one of the regions hardest hit by the pandemic, a better understanding of HIV and COVID-19 in the region is very much needed to target specific measures of prevention, continuity of care, and favorable outcomes among people with HIV.

Acknowledgements We would like to thank Alyssa Grymshaw for her support in the literature research.

\section{Declarations}

Conflict of Interest The authors declare no competing interests.

Human and Animal Rights and Informed Consent This article does not contain any studies with human or animal subjects performed by any of the authors.

\section{References}

Papers of particular interest, published recently, have been highlighted as:

- Of importance

$\bullet$ Of major importance

1. PGT Walker C Whittaker OJ Watson M Baguelin P Winskill A Hamlet 2020 The impact of COVID-19 and strategies for mitigation and suppression in low- and middle-income countries Science 3696502413422

2. AJ Rodriguez-Morales V Gallego JP Escalera-Antezana CA Méndez LI Zambrano C Franco-Paredes 2020 COVID-19 in Latin America: the implications of the first confirmed case in Brazil Travel Med Infect Dis. 35101613

3. Confirman el primer muerto por coronavirus en la Argentina: un hombre de 64 años que estuvo en Francia - LA NACION. La Nación [Internet]. [cited 2021 Feb 8]; Available from: https:// www.lanacion.com.ar/sociedad/confirman-primer-muerto-coron avirus-argentina-hombre-63-nid2341027/

4.•• PJ Garcia A Alarcón A Bayer P Buss G Guerra H Ribeiro 2020 COVID-19 response in Latin America Am J Trop Med Hyg 103 517651772 This article describes the common contextual factors in Latin America and the early responses to the pandemic in the region.

5. P Ssentongo AE Ssentongo ES Heilbrunn DM Ba VM Chinchilli 2020 Association of cardiovascular disease and 10 other preexisting comorbidities with COVID-19 mortality: a systematic review and meta-analysis PLOS ONE. 158 e0238215

6. Guan W, Liang W, Zhao Y, Liang H, Chen Z, Li Y, et al. Comorbidity and its impact on 1590 patients with Covid-19 in China: a nationwide analysis. European Respiratory Journal [Internet]. 2020 Jan 1 [cited 2021 Apr 15]; Available from: https://erj.ersjo urnals.com/content/early/2020/03/17/13993003.00547-2020

7. CC Chang M Crane J Zhou M Mina JJ Post BA Cameron 2013 HIV and co-infections Immunol Rev 2541114142

8. SW Cardoso TS Torres M Santini-Oliveira LMS Marins VG Veloso B Grinsztejn 2013 Aging with HIV: a practical review Braz J Infect Dis 174464479 
9. P Patel CE Rose PY Collins B Nuche-Berenguer VV Sahasrabuddhe E Peprah 2018 Noncommunicable diseases among HIV-infected persons in low-income and middle-income countries: a systematic review and meta-analysis AIDS 32 Suppl 1 S5 20

10. T Zhao K Xuan JP Uy C Sun 2021 In the shadow of COVID-19: HIV-infected individuals need more attention J Med Virol 932 611611

11. UNAIDS. AIDSinfo [Internet]. AIDSinfo. [cited 2021 Apr 16]. Available from: https://aidsinfo.unaids.org/

12. A Clark M Jit C Warren-Gash B Guthrie HHX Wang SW Mercer 2020 Global, regional, and national estimates of the population at increased risk of severe COVID-19 due to underlying health conditions in 2020: a modelling study Lancet Glob Health 88 e1003 e1017

13. LB Brown MA Spinelli M Gandhi 2021 The interplay between HIV and COVID-19: summary of the data and responses to date Curr Opin HIV AIDS 1616373

14. Boulle A, Davies M-A, Hussey H, Ismail M, Morden E, Vundle Z, et al. Risk factors for COVID-19 death in a population cohort study from the Western Cape Province, South Africa. Clin Infect Dis [Internet]. 2020 Aug 29 [cited 2021 Apr 15]; Available from: https://www.ncbi.nlm.nih.gov/pmc/articles/PMC7499501/

15. CE Espejo Ortiz YG Serrano Pinto JG Sierra Madero AL Iñiguez B Crabtree-Ramírez 2020381 HIV patients with COVID-19 hospitalized in a tertiary care center in Mexico City Open Forum Infect Dis. 7 Suppl 1 S260

16.• Ceballos ME, Ross P, Lasso M, Dominguez I, Puente M, Valenzuela P, et al. Clinical characteristics and outcomes of people living with HIV hospitalized with COVID-19: a nationwide experience. Int J STD AIDS. 2021;32(5):435-43. This is an observational study in Chile which recruited all PLWH with confirmed SARS-CoV-2 infection and hospitalized in 23 hospitals of eight regions.

17. MM Cipolat E Sprinz 2020 COVID-19 pneumonia in an HIVpositive woman on antiretroviral therapy and undetectable viral load in Porto Alegre Brazil Braz J Infect Dis 245455457

18. AJ Chiappe Gonzalez JJ Montenegro-Idrogo AR Vargas Vadillo M Slee Torres I Vargas Matos CP Resurrección Delgado 2020 Hospital-acquired SARS-CoV-2 pneumonia in a person living with HIV Int J STD AIDS 311313201322

19. B Cao Y Wang D Wen W Liu J Wang G Fan 2020 A trial of lopinavir-ritonavir in adults hospitalized with severe Covid-19 N Engl J Med 3821917871799

20. PW Horby M Mafham JL Bell L Linsell N Staplin J Emberson 2020 Lopinavir-ritonavir in patients admitted to hospital with COVID-19 (RECOVERY): a randomised, controlled, openlabel, platform trial The Lancet 3961025913451352

21. WHO Solidarity Trial Consortium, Pan H, Peto R, HenaoRestrepo A-M, Preziosi M-P, Sathiyamoorthy V, et al. Repurposed antiviral drugs for Covid-19 - interim WHO solidarity trial results. N Engl J Med. 2021;384(6):497-511.

22. RH Patel A Acharya M Mohan SN Byrareddy 2021 COVID-19 and AIDS: outcomes from the coexistence of two global pandemics and the importance of chronic antiretroviral therapy $\mathbf{J}$ Med Virol 932641643

23. J Amo Del R Polo S Moreno A Díaz E Martínez JR Arribas 2020 Incidence and severity of COVID-19 in HIV-positive persons receiving antiretroviral therapy : a cohort study Ann Intern Med 1737536541

24. de Sandes-Freitas TV, Cristelli MP, Neri B de O, Guedes ALM de O, Esmeraldo R de M, Garcia VD, et al. The unpredictable outcome of SARS-CoV-2 in kidney transplant recipients with HIV-infection. Transplantation. 2021;105(1):e9-10.

25. FJ Larzábal A Vilela S Brusca I Saluzzi GE Ghergo MA Angiono 2020 Simultaneous diagnosis and favorable evolution of infection with Pneumocystis jirovecii, SARS-CoV-2 and advanced HIV Medicina (B Aires) 805554556

26. BL Gómez 2011 Histoplasmosis: epidemiology in Latin America Curr Fungal Infect Rep 54199

27. Basso RP, Poester VR, Benelli JL, Stevens DA, Zogbi HE, Vasconcellos IC da S, et al. COVID-19-associated histoplasmosis in an AIDS patient. Mycopathologia. 2020;186:1-4.

28. M Bertolini MF Mutti JA Barletta A Falak D Cuatz A Sisto 2020 COVID-19 associated with AIDS-related disseminated histoplasmosis: a case report Int J STD AIDS 311212221224

29. Messina FA, Marin E, Caceres DH, Romero M, Depardo R, Priarone MM, et al. Coronavirus disease 2019 (COVID-19) in a patient with disseminated histoplasmosis and HIV-a case report from Argentina and literature review. J Fungi (Basel). 2020;6(4)

30. N Rivas M Espinoza A Loban O Luque J Jurado N Henry-Hurtado 2020 Case report: COVID-19 recovery from triple infection with Mycobacterium tuberculosis, HIV, and SARS-CoV-2 Am J Trop Med Hyg 103415971599

31. Gadelha Farias LAB, Gomes Moreira AL, Austregésilo Corrêa E, Landim de Oliveira Lima CA, Lopes IMP, de Holanda PEL, et al. Case report: coronavirus disease and pulmonary tuberculosis in patients with human immunodeficiency virus: report of two cases. Am J Trop Med Hyg. 2020;103(4):1593-6.

32. JL Tamuzi BT Ayele CS Shumba OO Adetokunboh J UwimanaNicol ZT Haile 2020 Implications of COVID-19 in high burden countries for HIV/TB: a systematic review of evidence BMC Infect Dis 201744

33. Chen Y, Wang Y, Fleming J, Yu Y, Gu Y, Liu C, et al. Active or latent tuberculosis increases susceptibility to COVID-19 and disease severity. medRxiv. 2020;2020.03.10.20033795.

34. World Health Organization. Global tuberculosis report 2020 [Internet]. Geneva: World Health Organization; 2020. Available from: https://www.who.int/publications/i/item/9789240013131

35. UNAIDS. Prevailing against pandemics by putting people at the centre - World AIDS Day report 2020 [Internet]. Available from: https://www.unaids.org/sites/default/files/media_asset/ prevailing-against-pandemics_en.pdf

36. Organization WH. COVID-19: operational guidance for maintaining essential health services during an outbreak: interim guidance, 25 March 2020. 2020 [cited 2021 May 31]; Available from: https://apps.who.int/iris/handle/10665/331561

37. World Health Organization. Maintaining essential health services: operational guidance for the COVID-19 context interim guidance [Internet]. World Health Organization; 2020 [cited 2020 May 8]. Available from: who.int/publications/i/item/ WHO-2019-nCoV-essential-health-services-2020.1

38. PAHO. Coronavirus disease 2019 (COVID-19) and HIV: key issues and actions - PAHO/WHO I Pan American Health Organization [Internet]. PAHO; 2020 [cited 2021 May 12]. Available from: https://www.paho.org/en/documents/coronavirus-disea se-2019-covid-19-and-hiv-key-issues-and-actions

39. World Health Organization. HIV self-testing [Internet]. [cited 2021 Apr 16]. Available from: https://www.who.int/hiv/topics/ self-testing/en/

40. Conserve DF, Mathews A, Choko AT, Nelson LE. Preparing for severe acute respiratory syndrome coronavirus 2 (SARSCoV-2) self-testing implementation: lessons learned from HIV self-testing. Front Med [Internet]. 2020 [cited 2021 Apr 16];7. Available from: https://www.frontiersin.org/articles/https://doi. org/10.3389/fmed.2020.599521/full

41. KR Billings DA Cort TD Rozario DP Siegel 2021 HIV stigma beliefs in context: country and regional variation in the effects of instrumental stigma beliefs on protective sexual behaviors in Latin America, the Caribbean, and Southern Africa Soc Sci Med. 269113565 
42. B Hoagland TS Torres DRB Bezerra M Benedetti C Pimenta VG Veloso 2021 High acceptability of PrEP teleconsultation and HIV self-testing among PrEP users during the COVID-19 pandemic in Brazil Braz J Infect Dis. 251101037

43.•• Paulino-Ramirez R. SARS-CoV-2 and HIV: convergence of two pandemics in the Caribbean. InterAmerican Journal of Medicine and Health [Internet]. 2020 Sep 29 [cited 2021 Apr 16];3. Available from: https://www.iajmh.com/iajmh/article/view/158 The authors describe the challenges the Caribbean countries are facing with COVID-19, but highlighting the HIV care in the Caribbean to reinvent the programmatic interventions and innovate to eliminate HIV transmission and improve services.

44. Lewis R, Blake C, Shimonovich M, Coia N, Duffy J, Kerr Y, et al. Disrupted prevention: condom and contraception access and use among young adults during the initial months of the COVID-19 pandemic. An online survey. BMJ Sex Reprod Health. 202111 ;

45. T Riley E Sully Z Ahmed A Biddlecom 2020 Estimates of the potential impact of the COVID-19 pandemic on sexual and reproductive health in low- and middle-income countries Int Perspect Sex Reprod Health 467376

46. I Dourado L Magno F Soares P Massa A Nunn S Dalal 2020 Adapting to the COVID-19 pandemic: continuing HIV prevention services for adolescents through telemonitoring Brazil AIDS Behav 24719941999

47. Luz PM, Benzaken A, de Alencar TM, Pimenta C, Veloso VG, Grinsztejn B. PrEP adopted by the Brazilian national health system. Medicine (Baltimore) [Internet]. 2018 May 25 [cited 2021 May 31];97(1 Suppl). Available from: https://www.ncbi.nlm.nih. gov/pmc/articles/PMC5991536/

48. Secretaría da Saúde - Governo do Estado Brasil. Orientações de prevenção e cuidado para as pessoas que vivem com HIV/ AIDS e serviços que atendem PHIV no contexto da pandemia do COVID-19 [Internet]. Goberno do Estado - Brasil; 2020 [cited 2021 May 12]. Available from: http://www.saude.ba.gov.br/wpcontent/uploads/2020/06/NT_n_51__HIV_AIDS__Servicos_ que_atendem_PHIV_no_contexto_da_pandemia.pdf

49. Torres TS, Hoagland B, Bezerra DRB, Garner A, Jalil EM, Coelho LE, et al. Impact of COVID-19 pandemic on sexual minority populations in Brazil: an analysis of social/racial disparities in maintaining social distancing and a description of sexual behavior. AIDS Behav. 2020;1-12.

50. Fernandes DE, Ferreira PRA, Mastroianni Kirsztajn G. Preexposure prophylaxis during the SARS-CoV-2 pandemic: can PrEP prevent COVID-19-related symptoms? Epidemiol Infect [Internet]. 2020 Sep 28 [cited 2021 May 12];148. Available from: https://www.ncbi.nlm.nih.gov/pmc/articles/PMC7556904/

51. GFM Pereira 2021 Brazil sustains HIV response during the COVID-19 pandemic Lancet HIV. 82 e65

52. Baral S, Rao A, Rwema JOT, Lyons C, Cevik M, Kågesten AE, et al. Competing health risks associated with the COVID-19 pandemic and response: a scoping review. medRxiv [Internet]. 2021 Jan 8 [cited 2021 May 9]; Available from: https://www. ncbi.nlm.nih.gov/pmc/articles/PMC7805463/

53. AB Hogan BL Jewell E Sherrard-Smith JF Vesga OJ Watson C Whittaker 2020 Potential impact of the COVID-19 pandemic on HIV, tuberculosis, and malaria in low-income and middleincome countries: a modelling study Lancet Glob Health 89 e1132 e1141

54. Dirección General de Regulación, Vigilancia y Control de la Salud, Departamento de los Programas de Atención a las Personas, Programa Nacional de Prevención y Control de ITS, VIH/SIDA. Lineamientos para Unidades de Atención Integral respecto al abordaje de la respuesta al $\mathrm{VIH}$, durante el estado de calamidad por la epidemia de coronavirus COVID-18
[Internet]. Ministerio de Salud Pública y Asistencia Social de Guatemala; 2020 [cited 2021 Apr 17]. Available from: http:// vihcentroamerica.org/sites/default/files/covid/GUA_Linea mientos_UAI_VIH_COVID19.pdf

55. Cai o número de casos e mortes causados pela Aids no país [Internet]. Governo do Brasil. [cited 2021 Apr 17]. Available from: https://www.gov.br/pt-br/noticias/saude-e-vigilanciasanitaria/2020/12/cai-o-numero-de-casos-e-mortes-causa dos-pela-aids-no-pais

56. Chang LR. Medidas de respuesta al VIH ante COVID-19 [Internet]. Programa Nacional de ITS/VIH/Sida; 2020. Available from: http://vihcentroamerica.org/sites/default/files/ covid/PAN_Medidas_Respuesta_VIH_COVID19.pdf

57. Secretaría de Salud. Directrices para asegurar el abastecimiento, distribución, dispensación y entrega de los medicamentos a las personas con VIH en los Servicios de Atención Integral (SAI), debido a la emergencia sanitaria por la pandemia de COVID-19 [Internet]. Gobierno de la República de Honduras; 2020. Available from: http://vihcentroamerica.org/ sites/default/files/covid/HON_Directrices_abastecimiento_ distribuci\%C3\%B3n_dispensacion_entrega_ARV.pdf

58. MA Benítez C Velasco AR Sequeira J Henríquez FM Menezes F Paolucci 2020 Responses to COVID-19 in five Latin American countries Health Policy Technol 94525559

59. JP Daniels 2020 COVID-19 threatens HIV care continuity in Brazil Lancet HIV 712 e804 e805

60. E Shadmi Y Chen I Dourado I Faran-Perach J Furler P Hangoma 2020 Health equity and COVID-19: global perspectives Int J Equity Health 191104

61. Siewe Fodjo JN, Villela EF de M, Van Hees S, Dos Santos TT, Vanholder P, Reyntiens P, et al. Impact of the COVID-19 pandemic on the medical follow-up and psychosocial well-being of people living with HIV: a cross-sectional survey. J Acquir Immune Defic Syndr. 2020;85(3):257-62.

62. Fallas H. Vivir con VIH en tiempos de COVID-19: Cuando los antirretrovirales urgentes llegan tarde - Radioemisoras UCR [Internet]. 2020 [cited 2021 Apr 17]. Available from: https://radios.ucr.ac.cr/2020/09/interferencia/vivir-con-vihen-tiempos-de-covid-19-cuando-los-antirretrovirales-urgen tes-llegan-tarde/

63.• Diaz MM, Cabrera DM, Gil-Zacarías M, Ramírez V, Saavedra M, Cárcamo C, et al. Knowledge and impact of COVID-19 on middle-aged and older people living with HIV in Lima, Peru. medRxiv. 2021;2021.04.23.21255998. This study found that nearly half of Peruvians living with HIV who were employed prior to the pandemic suffered job loss during the pandemic. Increased anxiety was reported in $64 \%$ and stress in $77 \%$. COVID-19 has had a substantial socioeconomic and mental health impact on PLWH.

64. Paulino-Ramirez R. SARS-CoV-2 and HIV: convergence of two pandemics in the Caribbean. InterAmerican Journal of Medicine and Health [Internet]. 2020 Sep 29 [cited 2021 Apr 16];3. Available from: https://www.iajmh.com/iajmh/article/view/158

65. K Celestin A Allorant M Virgin E Marinho K Francois JG Honoré 2021 Short-term effects of the COVID-19 pandemic on HIV care utilization, service delivery, and continuity of HIV antiretroviral treatment (ART) in Haiti AIDS Behav 1817

66. Person AK, Maruri F, Brazier E, Madero JGS, Rouzier V, Carriquiry G, et al. Describing the impact of the COVID-19 pandemic on HIV care in Latin America. Open Forum Infectious Diseases. 2020;7(Supplement_1):S303-4.

67. Siewe Fodjo JN, Villela EF de M, Van Hees S, Dos Santos TT, Vanholder P, Reyntiens P, et al. Impact of the COVID-19 pandemic on the medical follow-up and psychosocial well-being of people living with HIV: a cross-sectional survey. J Acquir Immune Defic Syndr. 2020;85(3):257-62. 
68. B Hoagland TS Torres DRB Bezerra A Garner K Geraldo L Freitas 2021 Acceptability of telemedicine and HIV self-test among PrEP users during the COVID-19 pandemic in Brazil J Int AIDS Soc 24 S1 3334

69. J Ballivian ML Alcaide D Cecchini DL Jones JM Abbamonte I Cassetti 2020 Impact of COVID-19-related stress and lockdown on mental health among people living with HIV in Argentina $\mathbf{J}$ Acquir Immune Defic Syndr 854475482

70. Santos G-M, Ackerman B, Rao A, Wallach S, Ayala G, Lamontage E, et al. Economic, mental health, HIV prevention and HIV treatment impacts of COVID-19 and the COVID-19 response on a global sample of cisgender gay men and other men who have sex with men. AIDS Behav. 2020;1-11.

71. AP Mahajan JN Sayles VA Patel RH Remien D Ortiz G Szekeres 2008 Stigma in the HIV/AIDS epidemic: a review of the literature and recommendations for the way forward AIDS 22 Suppl 2 S67 79

72. K Roelen C Ackley P Boyce N Farina S Ripoll 2020 COVID19 in LMICs: the need to place stigma front and centre to its response Eur J Dev Res 21121

73. A Perez-Brumer A Silva-Santisteban 2020 COVID-19 Policies can perpetuate violence against transgender communities: insights from Peru AIDS Behav 2713

74. W Heywood A Lyons 2016 HIV and elevated mental health problems: diagnostic, treatment, and risk patterns for symptoms of depression, anxiety, and stress in a national community-based cohort of gay men living with HIV AIDS Behav 20816321645

75. Jones DL, Ballivian J, Rodriguez VJ, Uribe C, Cecchini D, Salazar AS, et al. Mental health, coping, and social support among people living with HIV in the Americas: a comparative study between Argentina and the USA during the SARS-CoV-2 pandemic. Res Sq [Internet]. 2020 Nov 18 [cited 2021 Apr 16]; Available from: https://www.ncbi.nlm.nih.gov/pmc/articles/ PMC7685328/

76. DE Dow BT Mmbaga EL Turner JA Gallis ZJ Tabb CK Cunningham 2018 Building resilience: a mental health intervention for Tanzanian youth living with HIV AIDS Care 30 sup4 1220

77. Lotta G, Kuhlmann E. When informal work and poor work conditions backfire and fuel the COVID-19 pandemic: why we should listen to the lessons from Latin America. Int J Health Plann Manage. 2020 Dec 24;
78. P Somse PM Eba 2020 Lessons from HIV to guide COVID-19 responses in the Central African Republic Health Hum Rights 221371374

79. Chenneville T, Gabbidon K, Hanson P, Holyfield C. The impact of COVID-19 on HIV treatment and research: a call to action. Int J Environ Res Public Health [Internet]. 2020 Jun [cited 2021 Apr 15];17(12). Available from: https://www.ncbi.nlm.nih.gov/ pmc/articles/PMC7345635/

80. Paulino-Ramirez R, Tapia L. Learning from pandemics in the Americas: the Dominican Republic programmatic response against a novel coronavirus (COVID-19). InterAmerican Journal of Medicine and Health [Internet]. 2020 May 11 [cited 2021 Apr 15];3. Available from: https://www.iajmh.com/iajmh/artic le/view/104

81. Joint United Nations Programme on HIV/AIDS (UNAIDS). Rights in the time of COVID-19: lessons from HIV for an effective, community-led response [Internet]. Geneva: UNAIDS; 2020 [cited 2021 Apr 21] p. 15. Available from: https://www. unaids.org/sites/default/files/media_asset/human-rights-andcovid-19_en.pdf

82. WM El-Sadr 2020 What one pandemic can teach us in facing another AIDS 341217571759

83. Piron D. La experiencia cubana de lucha contra el VIH y su rol en el control de la covid [Internet]. Radio France International. 2020 [cited 2021 May 13]. Available from: https://www.rfi.fr/es/ am\%C3\%A9ricas/20201201-cuba-vih-sida-salud-covid-luchaepidemia

84 H Hansen 2003 Human immunodeficiency virus and quarantine in Cuba JAMA: The Journal of the American Medical Association. 2902128752875

85. A Nieves K Safreed-Harmon MA Torres 2020 HIV, COVID-19, and civil society: lessons from Venezuela's humanitarian crisis AIDS Rev 223148150

Publisher's Note Springer Nature remains neutral with regard to jurisdictional claims in published maps and institutional affiliations. 